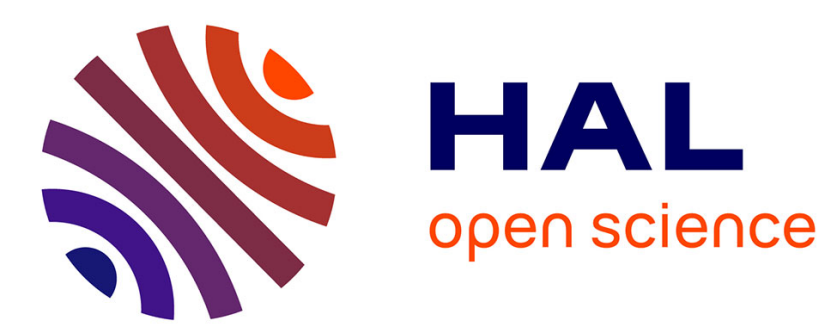

\title{
Modeling and Compensation of the Internal Friction Torque of a Travelling Wave Ultrasonic Motor
}

Frédéric Giraud, Paul Sandulescu, Michel Amberg, Betty Lemaire-Semail, Fiorin Ionescu

\section{> To cite this version:}

Frédéric Giraud, Paul Sandulescu, Michel Amberg, Betty Lemaire-Semail, Fiorin Ionescu. Modeling and Compensation of the Internal Friction Torque of a Travelling Wave Ultrasonic Motor. IEEE Transactions on Haptics (ToH), 2011, 4, pp.327-331. 10.1109/TOH.2011.20 . hal-00642523

HAL Id: hal-00642523

https://inria.hal.science/hal-00642523

Submitted on 28 Jan 2015

HAL is a multi-disciplinary open access archive for the deposit and dissemination of scientific research documents, whether they are published or not. The documents may come from teaching and research institutions in France or abroad, or from public or private research centers.
L'archive ouverte pluridisciplinaire HAL, est destinée au dépôt et à la diffusion de documents scientifiques de niveau recherche, publiés ou non, émanant des établissements d'enseignement et de recherche français ou étrangers, des laboratoires publics ou privés. 


\title{
Modeling and Compensation of the Internal Friction Torque of a Travelling Wave Ultrasonic Motor
}

\author{
Frédéric Giraud, Member, IEEE, Paul Sandulescu, \\ Michel Amberg, Betty Lemaire-Semail, Member, IEEE and Florin lonescu
}

\begin{abstract}
This paper deals with the control and experimentation of a one degree of freedom haptic stick, actuated by a travelling wave ultrasonic motor. This type of actuator has many interesting properties such as low speed operation capabilities and a high torque-to-weight ratio, making it appropriate for haptic applications. However, the motor used in this application displays non linear behaviour due to the necessary contact between its rotor and stator. Moreover, due to its energy conversion process, the torque applied to the end-effector is not a straightforward function of the supply current or voltage. This is why a force-feedback control strategy is presented, which includes an online parameter estimator. Experimental runs are then presented to examine the fidelity of the interface.
\end{abstract}

Index Terms-Force Feedback, Real Time Control, Haptic Display, Ultrasonic Motor.

\section{INTRODUCTION}

U LTRASONIC motors output high torque at low rotational speeds, and can thus be directly mounted on the lever of a 1 degree of freedom force feedback stick, without any speed reducer or cable driven system. Compared to classical electromagnetic solutions, which use a DC motor mounted with a speed reducer and cables, we can expect a reduction in the weight, backlash and bulk size of the kinematic chain. Moreover, they are built with non magnetic materials, providing a solution for force-feedback devices used in a Magnetic Resonance Imaging (MRI) environment [1][2][3]. Moreover the rotor is firmly pressed on the stator as a consequence of the design of the motors; thus, the shaft is locked if no power is applied to the motor. This property can be used in order to simulate stiff walls very easily. These advantages make Ultrasonic Motors a good alternative to other technologies in force-feedback applications.

However, these motors present many disadvantages due to their energy conversion process. In fact, the output torque is not a straightforward function of an electrical value. For DC motors, however, for which

- F. Giraud is with the University Lille1, F59000 Lille - France E-mail: frederic.giraud@polytech-lille.fr.

- P. Sandulescu is with the Arts \& Métiers Paris Tech , 8, boulevard Louis XIV 59046 Lille cedex.

E-mail: Alexandru-Paul.sandulescu-6@etudiants.ensam.eu.

- M. Amberg is with the University Lille1, F59000 France E-mail: michel.amberg@univ-lille1.fr.

- B. Lemaire-Semail is with the University Lille1, F59000 France E-mail: betty.semail@polytech-lille.fr.

- F. Ionescu is with University Polytechnica of Bucharest E-mail: florstef@yahoo.com. the output torque $T$ is proportional to the flowing current $I$ such that $T=K I$, the relationship cannot be applied for Ultrasonic Motors. Dry friction occurring at the stator-rotor interface is invoked to explain the torque production. But it is an extremely non linear process, which is difficult to model at very low speed. Torque production is thus a particular issue in these motors.

To cope with this problem, a specific control has to be designed in order to tune the output torque $T$ of the motor. For example, Schulte et al. built a haptic stick driven by a non-commercial Travelling Wave Ultrasonic Motor (TWUM)[4]. Results have shown good fidelity. But the control used a mapping of the torque versus speed characteristics of the motor. If the motor is replaced, a new identification process needs to be implemented. By mounting additional strain gauges that allow the measurement of the motor's torque, it is possible to propose a closed loop control which does not need a precise identification of the motor's torque-speed characteristics. Previous work has shown force feedback operations using such a control [5]. However, the loop corrector used was a simple PI which did not produce satisfactory control of the torque, even at low rotational speeds.

This article proposes a new control algorithm. It is based on the inversion of an accurate modelling which takes into account the internal friction torque. Accuracy of the loop corrector is thus improved by compensating this friction. To achieve this, it is necessary to identify the relationship between the friction and the operating conditions. A mean square algorithm is then used in order to identify on-line parameters of the friction modelling. 
In section 2 of this article, we present the modelling which includes friction, and the control scheme deduced from its inversion. This specific control includes a torque estimator which is also explained. Experimental runs are presented in section 3 .

\section{Modelling AND CONTROL}

\subsection{Modelling of a Travelling Wave Ultrasonic Mo- tor}

The travelling wave ultrasonic motor is driven by two sinusoidal voltages with a constant amplitude and variable pulsation. Two stationary waves are created by each voltage, one is combined with the other to produce a travelling wave. This wave is able to propel the rotor which is pressed on the stator. The speed of the rotor is a function of the vibration amplitude $W$ of each flexural wave, the phase shift $\varphi$ between the two supply voltages, and also depends on the operating conditions and on some parameters of the motor's design, such as the stator's thickness and the motor's diameter. This function is not straightforward, but under "ideal" contact conditions between the stator and rotor (no sliding and punctual contact conditions), the "ideal" rotational speed of the motor, called $\omega_{i d}$, would be:

$$
\mathbf{R}_{1} \rightarrow \omega_{i d}=\lambda W \sin (\varphi)
$$

where $\lambda$ is a coefficient taking into account the stator's geometry, and $-\frac{\pi}{2} \leq \varphi \leq \frac{\pi}{2}$. We note relation 1 as $\mathbf{R}_{1}$ because it is used later in a graphical representation.

Equation 1 is useful to obtain the motor's operating principle, but does not precisely describe its behaviour. In a previous study [6], we presented a modelling which takes into account the effect of the actual speed of the motor on the motor's output torque, and allowing us to write relation $\mathbf{R}_{2}$ as:

$$
\mathbf{R}_{2} \rightarrow T_{m}=f_{0}\left(\omega_{i d}-\omega\right)
$$

where

- $\omega$ is the revolving speed of the rotor

- $f_{0}$ is a parameter which is identified from the torque-speed characteristics of the motor

Relation 2 shows how the actual speed of the motor can be modified by the load torque. In fact, we can write $\omega=\omega_{i d}-\frac{T_{m}}{f_{0}}$ : if $\omega_{i d}$ is constant, $\omega$ decreases if $T_{m}$ increases. Under no load conditions, $T_{m}=0$ leads to $\omega=\omega_{i d}$ : using (1), the no load revolving speed of the motor should be a sinusoidal function of $\varphi$ for a constant vibration amplitude $W$ as depicted in figure 2, and a linear function of the vibration amplitude $W$ for constant $\varphi$. However, this behaviour is not verified by experimental measurements, such as those presented in figure 3. In fact, the actual motor presents a dead zone, which is a vibration amplitude below which the rotor sticks on the stator. In what follows, we call $W_{T H}$ the vibration threshold below which no revolution of the rotor is experienced.

In order to take into account these phenomena, one may use a non linear relationship instead of (1), as in [7]. But in this paper, we choose a linear relationship, and to include non linearities in an additional friction torque $T_{f}$ instead. Then $T_{f}$ is considered as a perturbation, and there exist online methods to identify and compensate it. The idea is to employ methods already used in force-feedback applications, and to synthesize torque controllers more easily for TWUM. So, the output torque of the motor $T$ is given by relation $\mathbf{R}_{3}$ :

$$
\mathbf{R}_{3} \rightarrow T=T_{m}-T_{f}
$$

In this modelling, $T_{f}$ is calculated in order to simulate the dead zone effect. To achieve this, we write:

$$
T_{f}=f_{0} \lambda W_{T H} \sin (\varphi) \quad \text { if } \quad W \geq W_{T H}
$$

For the no load condition $(T=0)$, and using (1), (2), (3) and (4), we can write:

$$
f_{0}\left(\omega_{i d}-\omega\right)=f_{0} \lambda W_{T H} \sin (\varphi)
$$

which yields:

$$
\omega=\lambda\left(W-W_{T H}\right) \sin (\varphi)
$$

For small vibration amplitudes below the threshold, $W \leq W_{T H}$, dry friction occurs and the rotor sticks to the rotor, leading to $\omega=0$. This behaviour is not modelled by equation 4 : the method proposed in the paper implies that we work above the threshold, and that we keep $W>W_{T H}$.

These relationships are consistent with experimental runs achieved on TWUM with a wave amplitude control [6]. In fact, if $W>W_{T H}$ and $\varphi=\frac{\pi}{2}, \omega$ is a linear function of $W$ and $\omega=0$ is reached for $W=W_{T H}$, as shown in figure 3. Moreover, for $W$ constant, $\omega$ varies with $\sin (\varphi)$ as depicted in figure 2 . Thus, this is proof for equation (4).

Finally, the dynamic of the angular velocity $\omega$ of the rotor is given by the dynamic mechanical equation, leading to relation $\mathbf{R}_{\mathbf{4}}$ :

$$
\mathbf{R}_{4} \rightarrow J \frac{d \omega}{d t}=T_{m}-T_{r}-T_{f}
$$

where $J$ is the inertia of the motor and $T_{r}$ the load torque. We represented this modelling in a Causal Ordering Graph [8] in order to deduce the torque control structure by inversion. In this graph, equations (1), (2), (3) and (7) are denoted by their causal relation $R_{1 . .4}$.

Of course, this is a very simplified modelling of the motor. But it can be verified by the experimental 


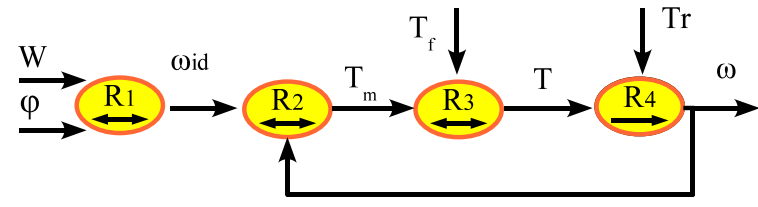

Fig. 1. Causal Odering Graph of the travelling Wave Ultrasonic Motor.

runs of figures 2 and 3 that the modelling matches the actual behaviour of the motor for steady state operations.

It is now possible to deduce, by inversion, the torque control, as is shown in the next section.

\subsection{Torque Control}

We can see from (2) that the output torque of the motor not only depends on supply conditions - leading to a certain vibration amplitude $W$ - but also on the actual speed of the motor $\omega$. A consequence of this is that to control the motor's output torque $\omega_{i d}$, and thus the supply conditions of the motor, should always be adapted to the actual speed $\omega$. Moreover, if the motor is not powered up, $\omega_{i d}=0$ : there exists a torque which blocks the motor's shaft. The energy supplied to the motor is thus necessary to overcome this high blocking torque. Hence, this modelling shows how a TWUM behaves differently

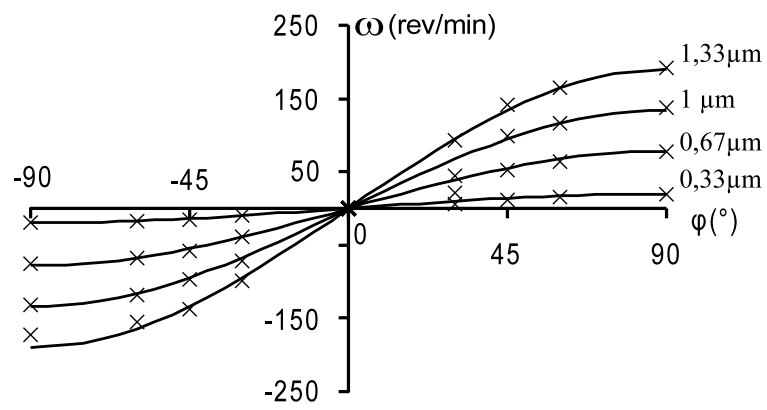

Fig. 2. No-load revolving speed as a function of $\varphi$ with $W$ constant. Comparison between modelling (solid lines) and experimental runs (crosses).

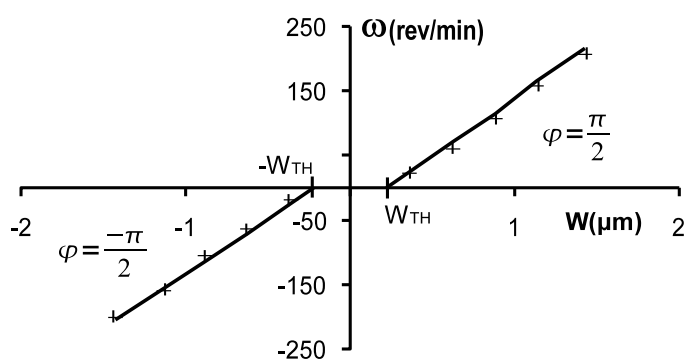

Fig. 3. No-load revolving speed as a function of $W$ with $\varphi$ constant. Comparison between modelling (solid lines) and experimental runs (crosses). to electromagnetic motors, where the current controls the torque independently of the rotor's velocity. It also points out how performances of a control can be different depending on wether we consider a force feedback application - for which the output torque should be controlled as precisely as possible - or a position control - for which $\omega=0$ is a mandatory condition at rest.

In [6], the torque controller directly adjusts $W$ from the error between the torque reference $T_{r e f}$ and $T$. The control scheme is simple, but the torque controller has to be finely tuned in order to exhibit the required performances. In this paper, we find the control scheme by inverting the causal ordering graph as in figure 4 . Starting from the torque $T$, we have first to invert $\mathbf{R}_{3}$ to calculate a reference for $T_{m}$, namely $T_{m r e g}$, which is directly deduced from relation $\mathbf{R}_{3}$, leading to equation 8 and relation $\mathbf{R}_{\mathrm{c}}$ :

$$
\mathbf{R}_{\mathrm{c} 3} \rightarrow T_{\text {mreg }}=T_{\text {ref }}+T_{f}
$$

Using the same approach, relations $\mathbf{R}_{2}$ and $\mathbf{R}_{\mathbf{1}}$ are inverted, leading to references for $\omega_{i d}, W$ and $\varphi$ ([7]). In this control scheme, no torque control is required. However, the control is accurate only if the friction torque $T_{f}$ is perfectly compensated. But large errors are experienced if parameters of equation (4) are not well identified. This is why this article deals with a torque estimator which is implemented on-line in a torque control of the travelling Wave Ultrasonic Motor.

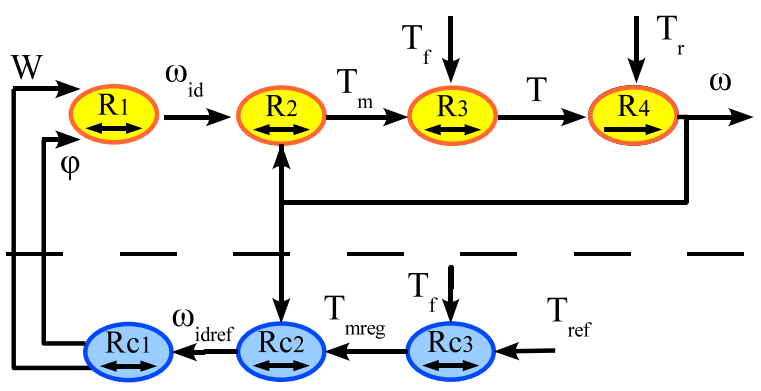

Fig. 4. Torque control (bottom part) and modelling (top part) of a TWUM.

\subsection{Parameter Estimator}

Many methods exist for implementing an estimation of the parameters of equation (3) [9], [10]. We have chosen to implement a least squares estimation method. Moreover, we will consider a recursive method because we are interested in identifying those parameters on-line.

In the context of TWUM, a measurement of the motor's output torque $T$ is achieved by strain gauges glued on the haptic stick. Then, equations (2),(3) and (4) lead to equation (9): 


$$
T=f_{0} \lambda W \sin (\varphi)-f_{0} \omega-f_{0} \lambda W_{T H} \sin (\varphi)
$$

The algorithm should estimate on-line parameters $f_{0}, W_{T H}$ and $\lambda$, from inputs $T, \omega, W$ and $\varphi$, which can be measured or regulated. We can build a vector matrix which contains the estimated values:

$$
X_{n}=\left(f_{0} \lambda,-f_{0},-f_{0} \lambda W_{T H}\right)^{T}
$$

where $\mathrm{n}$ defines the number of sampling periods. We also define a vector matrix with the measured data:

$$
A_{n}=(W \sin (\varphi), \omega, \sin (\varphi))
$$

The estimator should minimize $\left|A_{n} X_{n}-T\right|$. To achieve this, we define a square matrix $P$ which is updated upon the arrival of new data, as described in [11]:

$$
P_{n+1}=P_{n}-P_{n} \cdot A_{n}\left[A_{n}^{T} P_{n} A_{n}+1\right]^{-1} A_{n}^{T} P_{n}
$$

It is shown in [11] that $A^{T} P_{n} A$ is scalar, and the inverse is thus easily computable. It is useful to set:

$$
K_{n+1}=P_{n} \cdot A_{n}\left[A_{n}^{T} P_{n} A_{n}+1\right]^{-1}
$$

yielding:

$$
P_{n+1}=P_{n}-K_{n+1} A_{n}^{T} P_{n}
$$

The recursive method allows the calculation of the new vector of estimated values:

$$
X_{n+1}=X_{n}+P_{n+1} A_{n}\left(T-A_{n}^{T} X_{n}\right)
$$

where $T$ is the measured torque at the $\mathrm{n}$-th sampling period.

Simulation tests were carried out in order to check how long the algorithm takes to converge. We conclude that $2.5 \mathrm{sec}$ are necessary to converge at $100 \mu \mathrm{sec}$ of the sampling period. This is why this torque estimator adapts to slow drifts of the parameters, due to temperature for example. Thus, a faster torque controller is necessary to compensate for the modelling errors.

\subsection{Torque Controller}

Despite the online friction torque estimator, errors may still occur during transient operation; a torque controller is then added in parallel in order to reduce torque error. In this study, we used a simple PI controller, whose parameters are tuned to obtain a fast torque response. The final torque control scheme is detailed in figure 5 .

The block $R_{e}$ is used to compensate the friction torque estimation error. The output of $R_{e}$, which is called $T_{f \varepsilon}$ is then equal to the difference between the estimated friction torque $\tilde{T}_{f}$ and the actual one $T_{f}$. Because a perfect compensation of $T_{f}$ would result in

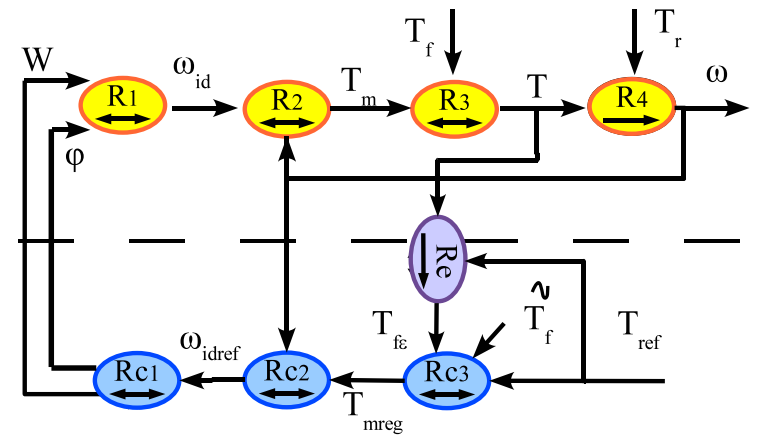

Fig. 5. Torque Control with a torque controller added. The torque estimator is not represented.

a perfect control of $T, T_{f \varepsilon}$ is then calculated from the difference between the actual output torque $T$ and its reference $T_{r e f}$, leading to:

$$
R e \rightarrow T_{f \varepsilon}=\left(K_{p}+\frac{K_{i}}{s}\right)\left(T_{r e f}-T\right)
$$

The two blocks $R_{c 1}, R_{c 2}$ describe the inversion of the relations $R_{1}$ and $R_{2}$; they are not detailed in this paper, but information about their synthesis can be found in [7]. Finally, this control scheme produced an experimentally measured response time of about $3 \mathrm{~ms}$ for the closed loop torque control.

\section{IMPEDANCE FIDELITY TEST}

\subsection{Experimental Setup}

A one-degree-of-freedom force feedback lever was built to verify the control laws. The experiment involves use of the lever of the digitracker which is free to rotate about the horizontal axis, and is presented in figure 6 . On the shaft, we attached a variable resistor which outputs a voltage proportional to the angular position of the lever (a $2 k \Omega$ low friction resistor from Vishay, $N^{0} 1$ in figure 6). On the right hand side of the figure, the TWUM is fixed to the shaft $\left(N^{0} 2\right.$ in figure 6) in order to achieve force feedback operations. The motor used is a Shinsei USR30, its technical specifications are presented in table 1.

TABLE 1

technical specifications of a Shinsei USR 30

\begin{tabular}{|c|c|}
\hline rated torque & $0.1 \mathrm{Nm}$ \\
\hline rated speed & $200 \mathrm{rev} / \mathrm{min}$ \\
\hline supply voltage & $200 \mathrm{volts}$ \\
\hline supply frequency & $50 \mathrm{kHz}$ \\
\hline outer diameter & $30 \mathrm{~mm}$ \\
\hline
\end{tabular}

In order to measure the torque of the motor, two strain gauges (CEA 13015 UW, $120 \Omega$ from Vishay) were bonded on the lever, yielding a torque sensor. The measured torque differs from $T$ by a small amount due to the small shaft and the position sensor friction, and shaft inertia, which are negligible compared to the lever's inertial torque. 


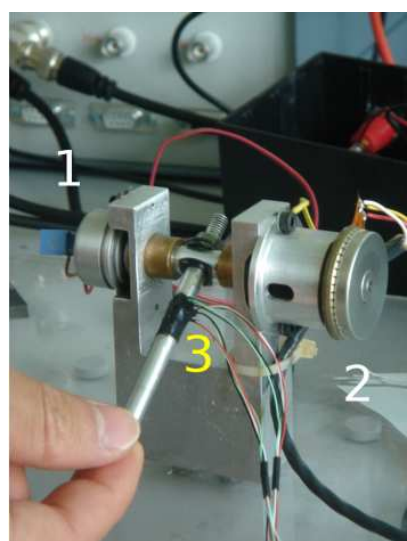

Fig. 6. The experimental test setup. 1: position sensor 2: TWUM 3: Strain gauges.

The motor is supplied by a linear power amplifier. Typical voltage frequency is $50 \mathrm{kHz}$, but this value may vary from $55 \mathrm{kHz}$ to $49 \mathrm{kHz}$. On the motor, a deformation sensor is bonded on the stator. This sensor is used for the deformation amplitude control. The control laws are computed on a DSP SBC6711 board; $W$ is regulated by a closed loop control whose response time is estimated to be constant and equal to $1 \mathrm{~ms}$. More details about this control can be found in [6]. We chose a sampling period of $100 \mu \mathrm{sec}$. Two electronic boards were built to adapt analog input and output to the motor. First, a rectifying amplifier converts the voltage from the sensor to the DSP. A second one is based on a Voltage Controlled Oscillator, and converts a voltage from the DSP to a frequency of two sinusoidal voltages with the same amplitude. Finally, a digital output of the DSP is used to modify the voltages' phase differences. This control hardware is shown in figure 7 .

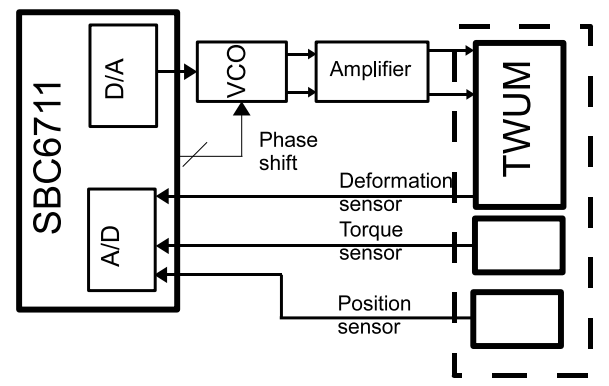

Fig. 7. The hardware setup.

\subsection{Experimental results and discussion}

If no power is applied to the stator, the motor is locked in its position because the rotor is pressed on the stator. Consequently, simulating a zero torque on the lever is something which is not natural, and which demonstrates how well friction compensation is achieved. This is why, during this test session, the

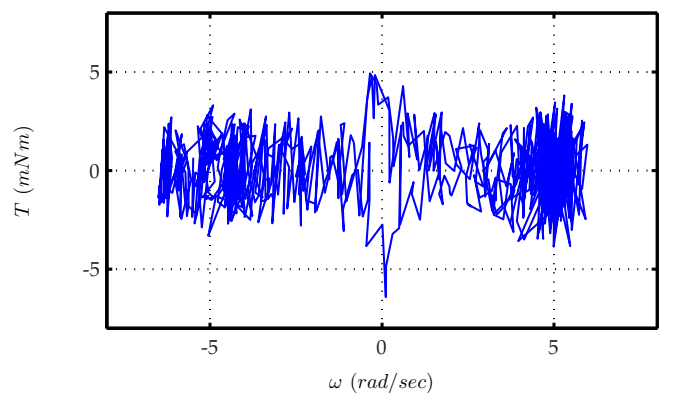

Fig. 8. $T$ as a function of $\omega$ when $T_{r e f}=0$.

torque reference is set to 0 . The user should then be free to manipulate the lever at any speed condition. Results are presented in figure 8, in the torque-speed plane. As can be seen, a zero force is achieved. However, when the motor's speed reverses, a torque spike evaluated at $5 \mathrm{mNm}$ appears. This spike is due to the difficulty which exists in removing the motor's static friction. These spikes are small compared to the motor's rated torque. But this figure can increase if the user's rotational speed becomes faster, and can increase up to $15 \mathrm{mNm}$.

Experimental data from controlled viscous friction tests are presented in figure 9. During this test, we set $T_{r e f}=f_{v} \omega$ where $f_{v}$ is the parameter used to obtain the desired friction. Low to high friction levels were programmed, leading to several values of $f_{v}=$ such as $f_{v}=0.0001,0.001,0.01,0.1 \mathrm{Nm} . \mathrm{sec}$. In the torquespeed plane, characteristics of the measured torque $T$ should then be straight lines. This is actually the case except around $\omega=0$ and for low friction. In fact, in that case, the parasitic torque leading to the spike is relevant. These spikes decrease the fidelity of the haptic interface.

Finally, we created an elastic virtual environment, by imposing $T_{r e f}=K_{v} \theta+f_{v} \omega$. Some friction was added in order to stabilize the virtual stiffness, however its value was sufficiently low not to change the elastic behavior. Results are presented in figure 10. They show that the measured torque is close to its reference; no hysteresis appears in the torqueposition plane, showing that motor's static friction is well compensated. For the $K_{v}=5.7 \mathrm{Nm} / \mathrm{rad}$ case, we required the user to be stronger than the forcefeedback device. By doing so, the motor saturates and the output torque attains its limit. This results in horizontal lines in the torque-position plane. One may remark that the torque limit is smaller than the motor's rated torque $(100 \mathrm{~m} \mathrm{Nm})$. During these experiments, the friction torque estimator was running. We have drawn its output as a function of time to verify its accuracy. We compare in figure 11 the calculated friction torque from (4) to the measured one. In fact, from (3), we obtain $T_{f}=T_{m}-T$. This is not a direct measurement of $T_{f}$, but it should be equal to $\tilde{T}_{f}$ if the 

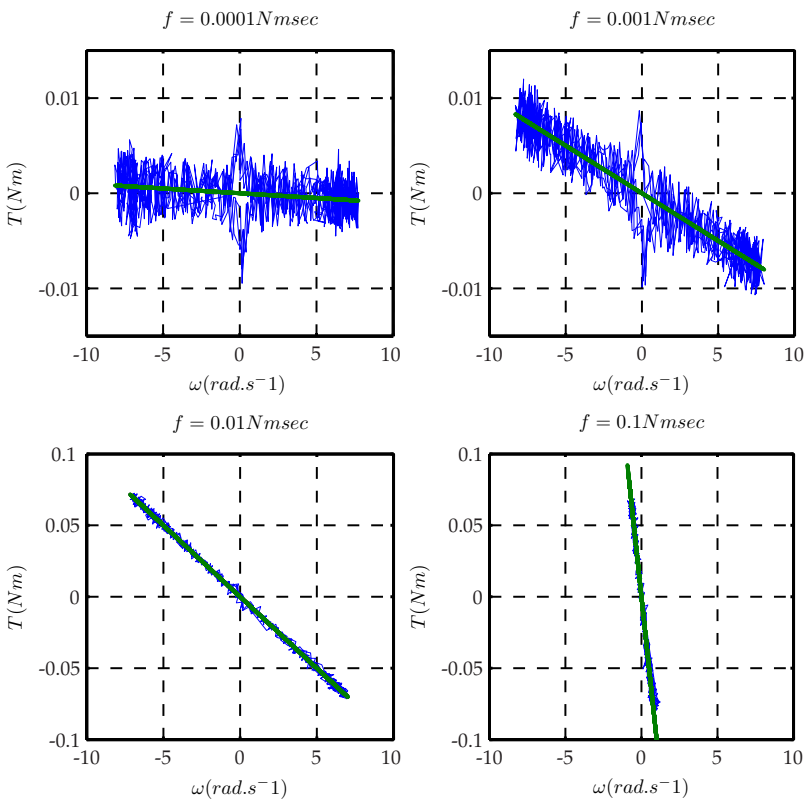

Fig. 9. $T$ as a function of $\omega$ for $T_{r e f}=f_{v} \omega$.
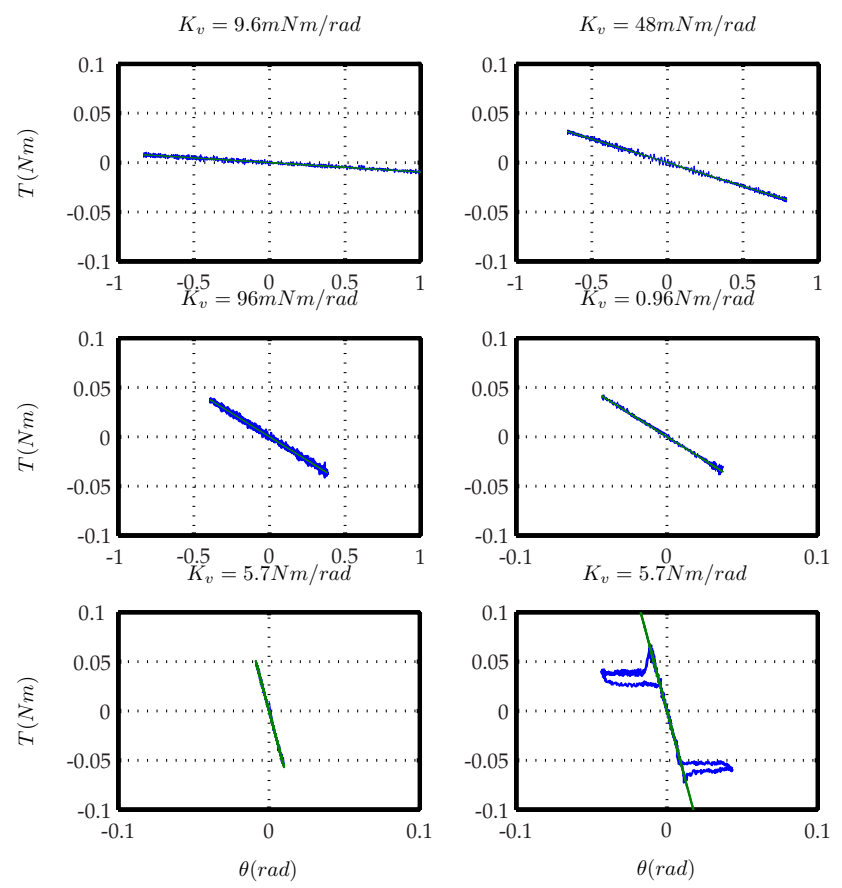

Fig. 10. $T$ as a function of $\theta$ when $T_{r e f}=K_{v} \theta+f_{v} \omega$.

estimation is perfect.

Thus, the friction estimator is accurate because the estimated value of $T_{f}$ is very close to the measured one. Moreover, the parameter estimator is helpful to follow the slow drifts of $T_{f}$ and to estimate these parameters without a specific measurement process. In the end, the error between $T_{r e f}$ and $T$ is small at the input of the torque controller $\mathbf{R}_{\mathbf{e}}$. If we remove the friction torque estimation, then fidelity of the forcefeedback device only relies on the torque controller
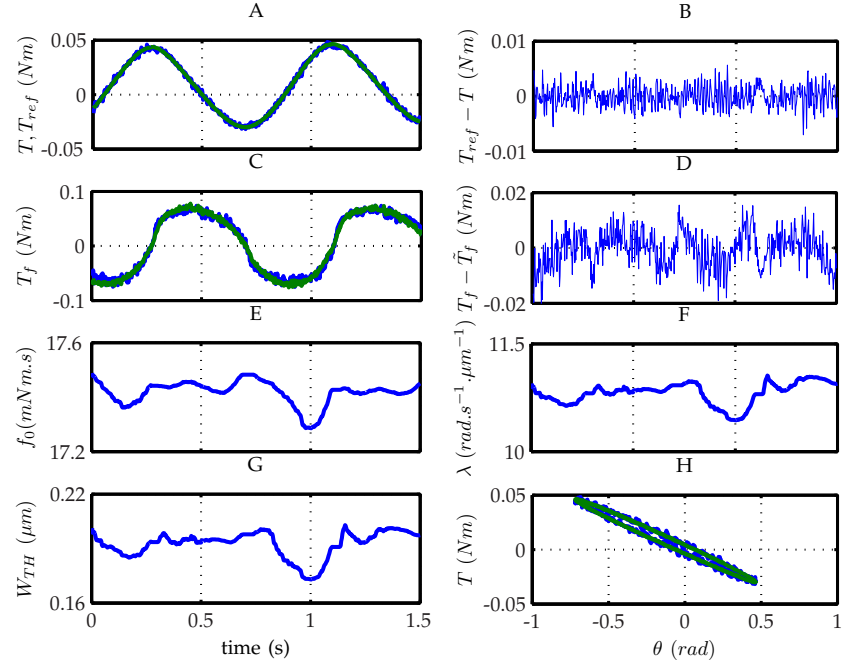

Fig. 11. Transitory operation of the force-feedback device. $A$ and $B$ : comparison between $T$ and $T_{\text {ref }} ; C$ and $D$ : comparison between $\tilde{T}_{f}$ and $T ; E, F$ and $G$ : estimation of $f_{0}, \lambda$ and $W_{T H}$ of equations 3 and 4 , and $\mathrm{H}$ : $T$ as a function of $\theta$.

$\mathbf{R}_{\text {e. }}$ In that case, large torque errors are measured at each change in direction of the lever, as those shown in figure 12. Consequently, in the $T-\theta$ plane, the spikes that appear are those presented in [6]. This test shows the experimental performance of the estimator because we obtain a satisfactory torque control of the motor even without a high-performance torque controller.
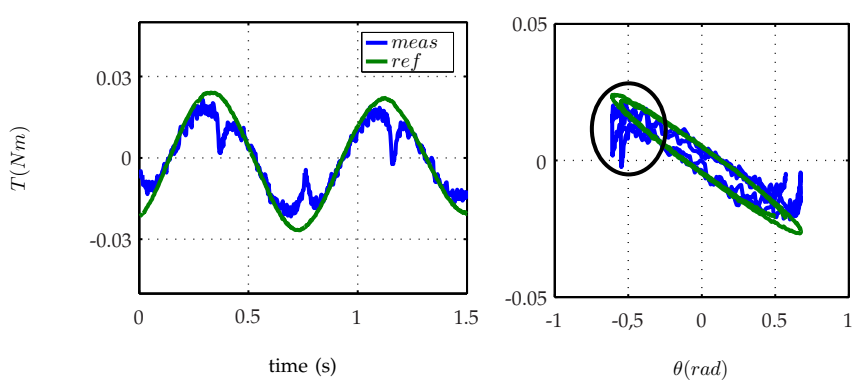

Fig. 12. Output torque $T$ compared to $T_{\text {ref }}$ when the friction torque estimator is removed. The ellipse highlights errors when the direction changes.

\section{Conclusion}

This paper presents a control algorithm for a travelling wave ultrasonic motor used during force feedback operations. This control compensates internal friction of the motor, and uses an online friction estimator. An experimental test bench was designed and has shown that the motor could be directly mounted on the haptic stick to allow force-feedback. The control presented good performances at low rotational speed. Despite not being able to avoid the spike that arises when the rotational speed reverses, we measured 
torque spikes of $5 \mathrm{mNm}$ which is low compared to the maximum output torque. We then simulated a variable stiffness spring. The largest simulated stiffness was set to $1.92 \mathrm{Nm} / \mathrm{rad}$ and we imposed torque limitation of the motor at $0.05 \mathrm{Nm}$ which is lower than its rated torque.

These performances were obtained with a commercial product. They may encourage use of Travelling Wave Ultrasonic Motors in force-feedback applications in order to reduce the weight or bulk size of the system. To attain better performances, work needs to be carried undertaken in order to improve the motor's control. To reach the same performance level of today's force-feedback device, a specific design of the motors may however also be necessary.

\section{REFERENCES}

[1] M. Flueckiger, M. Bullo, D. Chapuis, R. Gassert, and Y. Perriard, "fmri compatible haptic interface actuated with traveling wave ultrasonic motor," in Conference Record of the 40th IAS Annual meeting, vol. 3, october 2005.

[2] S. Klare, A. Peer, and M. Buss, "Development of a 3 dof mrcompatible haptic interface for pointing and reaching movements," in EuroHaptics 2010, Part II, LNCS 6192, 2010, pp. 211218.

[3] J. Izawa, T. Shimizu, T. Aodai, T. Kondo, H. Gomi, S. Toyama, and $\mathrm{K}$. Ito, "Mr compatible manipulandum with ultrasonic motor for fmri studies," in Robotics and Automation, 2006. ICRA 2006. Proceedings 2006 IEEE International Conference on, May 2006, pp. $3850-3854$.

[4] T. Schulte, H.Grostollen, H.-P. Schöner, and J.-T. Audren, "Active control stick driven by a piezo electric actuator," $3 r d$ Int. symposium on advanced electromechanical motion systems, vol. 1, pp. 583-588, Jul. 1999.

[5] Z. Dai, F. Giraud, B. Lemaire-Semail, and F. Martinot, "A force feedback device actuated by piezoelectric travelling wave ultrasonic motors," in 10th International Conference on New Actuators, ACTUATOR'06, Jun. 2006, pp. 600-603.

[6] F. Giraud, B. Semail, and J.-T. Audren, "Analysis and phase control of a piezoelectric traveling-wave ultrasonic motor for haptic stick application," IEEE Transactions on Industry Applications, vol. 40, no. 6, pp. 1541-1549, Nov. Dec. 2004.

[7] F. Giraud, B. Semail, J. Aragones, J. Robineau, and J.-T. Audren, "Precise position control of a traveling-wave ultrasonic motor," IEEE Transactions on Industry Applications, vol. 43, no. 4, pp. 934-941, Jul. 2007.

[8] P.-J. Barre, A. Bouscayrol, P. Delarue, E. Dumetz, F. Giraud, J.-P. Hautier, X. Kestelyn, B. Lemaire-Semail, and E. Semail, "Inversion-based control of electromechanical systems using causal graphical description," IEEE IECON'2006, Nov. 2006.

[9] A. Janot, P. Vandanjon, M. Gautier, and F. Khatounian, "Analysis and application of a robust identification method," in IEEE International Symposium on Computational Intelligence in Robotics and Automation, Jun. 2006, pp. 315-320.

[10] D. S. Kwon and K. Y. Woo, "Control of the haptic interface with friction compensation and its performance evaluation," in IEEE/ RSJ International Conference on Intelligent Robots and Systems, 2006, pp. 955-960.

[11] W. Y. Yang, W. Cao, T.-S. Chung, and J. Morris, Applied Numerical Methods Using MATLAB. Wiley-Interscience, 2005.

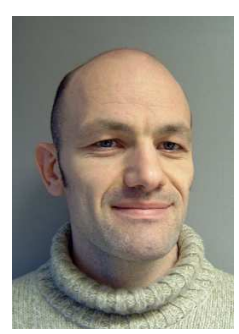

Frédéric Giraud (BS'95 Paris-XI University, MS'97 Institut National Polytechnique de Toulouse) graduated from the Ecole Normale Supérieure de Cachan, France in 1996 in electrical engineering, and received his $\mathrm{PhD}$ from the University Lille1, in 2002. He is a member of the electrical engineering and power electronics laboratory of Lille where he works as an Associate Professeur. His research deals with the modelling and the control of piezo-electric actuators.

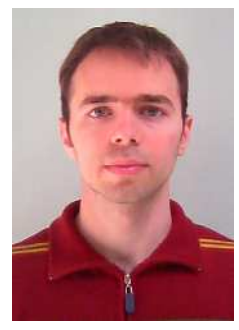

Paul Sandulescu was born in Bucharest, Romania in 1986. He studied electrical engineering at the University Politechnica of Bucharest where he obtained the title of Engineer in electrical engineering, specializing in electrical machines, drive systems and power electronics. He is now a PhD student working on multiphase electrical machine controls at the L2EP laboratory (Arts et Metiers ParisTech). His main research inmachines drive systems. terests are Power Electronics and Multiphase

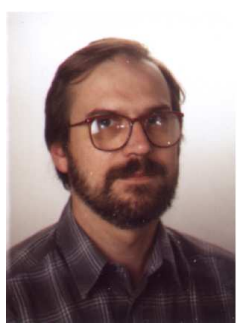

Michel Amberg teaches electronics at the University of Lille, France. He graduated from Ecole Normale Supérieure de Cachan, France in 1981. He has tutored more than a hundred Bachelor Students during their projects in the field of telecommunications, computer science and electronics. He is now research engineer at IRCICA, and works on the electronic design of tactile devices.

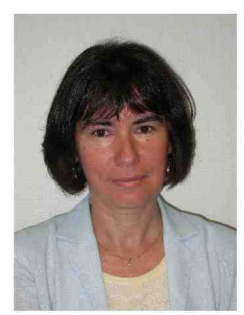

Betty Lemaire-Semail (Ph.D'90, University of Paris XI, Orsay). From 1990 to 1998, she was assistant professor in the Ecole Centrale of Lille and she is now professor at the University Lille1. She is a member of the electrical engineering and power electronics laboratory of Lille and head of the research axis on the control of electrical systems. She has studied electromagnetic motors and her main field of interest now deals with the modelling and control of piezoelectric actuators, for positioning and force feedback applications.

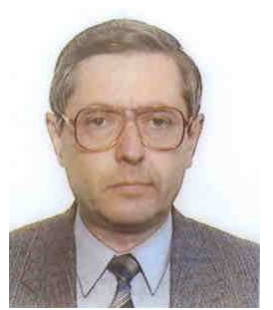

Florin lonescu received his Ph.D in electrical engineering from the Faculty of Electrical Engineering, University Politechnica of Bucharest (UPB), Romania, in 1978. He is currently a Full Professor in the power converters field with the Faculty of Electrical Engineering, UPB. He is author or co-author of more then 100 technical papers and reports and 27 books and textbooks. He was a visiting Professor with GREAH Laboratory, University of Havre, France in 1998 and 2000 and with Polytech'Lille, Villeneuve d'Ascq, France in 2004, 2005 and 2007. His current research interests include topologies for DC-DC power converters and switch-mode power supplies. 